\title{
ANALISIS TERAPI AKUPRESURE TERHADAP KESEIMBANGAN GLUKOSA DARAH PADA PASIEN DIABETES MELITUS TIPE 2 DI WILAYAH KERJA PUSKESMAS JUMPANDANG BARU MAKASSAR
}

\section{ANALYSIS OF ACUPRESSURE THERAPY ON BLOOD GLUCOSE BALANCE IN DIABETES MELITUS TYPE 2 AT PUSKESMAS JUMPANDANG BARU MAKASSAR}

\author{
Maryam Jamaluddin, Wahyuni Maria Prasetyo \\ STIKES Nani Hasanuddin Makassar
}

Maryamiyang99@yahoo.co.id/082347917574

\begin{abstract}
$D M$ is a metabolic disease that can cause various complications. This situation greatly affects the quality of life of people with DM so it needs to get serious attention from all parties. The purpose of this study was to determine the effect of Accupresure on blood glucose balance in DM patients in the working area of Makassar Public Health Center. This study uses a Quasy Experiment research design in the form of Nonequivalent Control Group Design. This research was carried out at the Jumpandang Baru Public Health Center in Makassar from June to September. In this study the population is all people with Diabetes Mellitus in the Jumpandang Baru Makassar working area. From this population then a number of samples were taken to be respondents based on consecutive sampling with the sample size using the Wilcoxon table with a significance level of 5\%, at least 6 samples, with consideration of the sample dropping out and the strength of the sample, the researchers took 15 samples in each intervention group and control. The results obtained showed that there was a significant influence in the administration of acupressure therapy on blood glucose balance in type 2 DM patients with a value of $p=0.005$ in the intervention group and $p=0.977$ in the control group. Acupressure therapy is proven to be able to reduce blood glucose and is very helpful for reducing complications due to diabetes. Acupressure therapy is considered as the most effective alternative therapy for controlling diabetes compared to other therapies. Acupressure has been shown to reduce blood glucose and is very helpful in reducing complications due to diabetes. Combined therapy (acupressure therapy, hypnotherapy, and Transcendental Meditation) may be important in the population of type 2 diabetes patients for advanced psycho-physiological therapy.
\end{abstract}

Keywords: Acupressure, DM type 2, Hba1C

\section{ABSTRAK}

Penyakit DM merupakan penyakit metabolik yang dapat menimbulkan berbagai komplikasi. Keadaan ini sangat memengaruhi kualitas hidup penyandang DM sehingga perlu mendapatkan perhatian serius dari semua pihak. Tujuan penelitian ini adalah Untuk mengetahui pengaruh Accupresure terhadap keseimbangan glukosa darah pasien DM diwilayah kerja puskesmas Makassar. Penelitian ini menggunakan rancangan penelitian Quasy Experiment dengan bentuk Nonequivalent Control Group Design. Penelitian ini telah dilaksanakan di Puskesmas Jumpandang Baru Makassar pada bulan Juni sampai dengan September. Pada Penelitian ini populasinya adalah seluruh penderita Diabetes Melitus yang ada di wilayah kerja Jumpandang Baru Makassar. Dari populasi tersebut kemudian di ambil sejumlah sampel untuk dijadikan responden berdasarkan consecutive sampling dengan besaran sampel menggunakan tabel wilcoxon dengan tingkat kemaknaan $5 \%$ yaitu minimal 6 sampel, dengan pertimbangan sampel yang drop out dan kekuatan sampel maka peneliti mengambil 15 sampel dalam masing-masing kelompok intervensi dan kontrol. Hasil penelitian yang diperoleh menunjukkan ada pengaruh yang signifikan pemberian terapi akupresure terhadap keseimbangan glukosa darah pada pasien DM tipe 2 dengan nilai $p=0.005$ pada kelompok intervensi dan $p=0.977$ pada kelompok control. Terapi akupresur terbukti mampu mengurangi glukosa darah dan sangat membantu untuk mengurangi komplikasi akibat diabetes, Terapi akupresur dianggap sebagai terapi alternative yang paling efektif untuk mengontrol diabetes dibandingkan dengan terapi lainnya. Akupresur terbukti mampu mengurangi glukosa darah dan sangat membantu untuk mengurangi komplikasi akibat diabetes. Terapi gabungan (terapi akupresur, hipnoterapi, dan Transcendental Meditation) mungkin penting pada populasi pasien diabetes tipe 2 untuk terapi psiko-fisiologis tingkat lanjut.

Kata kunci : Akupresur, DM tipe 2, Hba1C

\section{PENDAHULUAN}

Federasi Diabetes Internasional (IDF) memperkirakan bahwa penderita Diabetes Melitus (DM) pada tahun 2035 akan meningkat menjadi 592 juta. $80 \%$ tinggal di negara berpenghasilan rendah dan menengah, dan dari total lebih dari $60 \%$ tinggal di Asia (Ramachandran et al., 2016). Diperkirakan dari 382 juta orang yang hidup dengan diabetes, 175 juta diantaranya belum terdiagnosa, sehingga terancam berkembang progresif menjadi komplikasi tanpa disadari dan tanpa pencegahan (Pusat Data dan Informasi Kesehatan, 2014).

Di Indonesia berdasarkan data Riskesdas 2013, menunjukkan bahwa terjadi peningkatan prevalensi diabetes dari 1,1 persen di tahun 2007 menjadi 2,1 persen pada tahun 2013, dan diperkirakan akan terus meningkat. Sulawesi Selatan berada 
pada posisi ke 2 perkiraan jumlah pasien DM yang belum terdiagnosa oleh dokter, namun telah menderita DM 1 bulan terakhir, dan urutan ke 14 berdasarkan jumlah pasien yang terdiagnosa (KemenKes, 2014). Berdasarkan data dari dinas kesehatan kota Makassar kasus baru yang ada adalah 4.224 pasien, dari sepuluh urutan teratas kejadian DM yang ada di seluruh puskesmas di Makassar Puskesmas jumpandang Baru merupakan yang paling tinggi kejadian DM nya.

Penyakit DM merupakan penyakit metabolik yang dapat menimbulkan berbagai komplikasi Keadaan ini sangat memengaruhi kualitas hidup penyandang DM sehingga perlu mendapatkan perhatian serius dari semua pihak. DM merupakan penyakit menahun yang akan disandang seumur hidup. Dengan berbagai permasalahan yang dihadapi, misalnya dengan Poliuria, polidipsia, polifagia dan penurunan berat badan yang tidak dapat dijelaskan sebabnya. Keluhan lainnya adalah lemah badan, kesemutan, gatal, mata kabur, dan disfungsi ereksi pada pria, serta pruritus vulva pada wanita. Selama ini penanganan pasien DM dikendalikan dengan dengan cara diet, olahraga dan dengan menggunakan obat antidiabeteik (Rudijanto et al., 2015), namun hal ini tidak membuat penderita DM berkurang.

Penanganan lain yang bisa dilakukan untuk menjaga keseimbangan glukosa darah pasien adalah dengan memberikan terapi komplementer, terapi komplementer adalah berrbagai terapi alami yang digunakan untuk meningkatkan kesehatan, penyembuhan dan kesejahteraan, melengkapi perawatan medis yang berfokus pada penyakit salah satunya terapi akupresur. Terapi akupresure biasa digunakan untuk meningkatkan kualitas tidur pasien, hal ini berhubungan secara tidak langsung dengan kontrol glukosa darah pada pasien DM dimana kualitas tidur yang buruk dan tidur kurang efisien mempengaruhi kontrol yang buruk terhadap tingkat $\mathrm{HbA} 1 \mathrm{c}$ pada diabetes tipe 2. Perbaikan kualitas tidur pada pasien DM dapat menyebabkan kontrol glikemik yang jauh lebih baik dari pasien serta peningkatan kualitas hidup (Tsai et al., 2012).

Terapi akupresure dianggap sebagai terapi alternative yang paling efektif untuk mengontrol diabetes dibandingkan dengan terapi lainnya yakni $67,8 \%$ dari 494 responden yang diteliti (Mehrotra \& Bajaj,
2004). Hal ini dibuktikan juga oleh penelitian yang dilakukan (Fitrullah \& Rousdy, 2016) yang menyatakan terapi akupresur terbukti mampu mengurangi glukosa darah dan sangat membantu untuk mengurangi komplikasi akibat diabetes, hal yang sama di kemukakan oleh (Chen et al., 2009) yang menyatakan bahwa akupresur merupakan strategi tambahan nonfarmakologis yang efektif untuk mengurangi perkembangan dan komplikasi terkait diabetes melitus tipe 2. Sebuah penelitian lain menunjukkan bahwa terapi psiko-fisiologis gabungan (terapi akupresur, hipnoterapi, dan Transcendental Meditation) mungkin penting pada populasi pasien diabetes tipe 2 untuk terapi psiko-fisiologis tingkat lanjut (Bay \& Bay, 2011).

\section{METODE}

\section{Desain, tempat dan waktu}

Desain penelitian ini menggunakan rancangan penelitian Quasy Experiment dengan bentuk Nonequivalent Control Group Design, Dimana desain ini memungkinkan peneliti untuk membandingkan antara Kontrol glukosa pada pasien DM yang diberikan pengobatan biasa ditambah intervensi akupresur dengan yang menjalani pengobatan biasa, (Soekidjo Notoatmojo, 2005).

Penelitian ini dilakukan di Puskesmas Jumpandang Baru Makassar pada bulan Juni sampai dengan September.

\section{Populasi dan Subjek Penelitian}

Pada Penelitian ini populasinya adalah seluruh penderita Diabetes Melitus yang ada di wilayah kerja Jumpandang Baru Makassar. dengan pertimbangan sampel yang drop out dan kekuatan sampel maka peneliti mengambil 15 sampel dalam masing-masing kelompok intervensi dan kontrol. Jadi, digunakan 30 sampel

\section{Jenis dan Cara Pengumpulan Data.}

Data yang diambil merupakan data primer, yang diperoleh dengan mengukur $\mathrm{HbA1c}$ dari responden sebelum dilakukan intervensi baik pada kelompok control maupun pada kelompok intervensi, selanjutnya pengukuran dilakukan kembali setelah intervensi selesai dilakukan yaitu 3 bulan berikutnya. 


\section{Pengolahan dan analisis data}

Uji analisis data untuk melihat perbedaan control glukosa pada pre dan post baik pada kelompok kontrol maupun intervensi yaitu uji $t$ dependent jika sebaran data normal atau uji alternatif wilcoxon jika sebaran data tidak normal dengan tingkat signifikansi ditetapkan $p<0.05$. Untuk melihat perbedaan glukosa darah pada kelompok kontrol dan intervensi maka digunakan uji $t$ independen jika sebaran data normal atau uji alternatif mann whitney jika sebaran data tidak normal. Normalitas data dinilai dengan melihat hasil skewness melalui olah SPSS

\section{HASIL}

\section{Analisis Univariat}

1. Umur

Umur responden yang paling muda yaitu 42 tahun dan yang paling tua yaitu 63 tahun dengan median 53 tahun,

2. Pendidikan

Pendidikan responden yang paling banyak adalah SMA yaitu sebanyak 10 responden dengan presentasi $33.3 \%$.

3. Pekerjaan

Data pekerjaan responden menunjukkan bahwa pekerjaan yang paling banyak dikerjakan oleh responden adalah wiraswasta yaitu 11 atau $36.7 \%$ responden.

4. Jenis Kelamin

Perempuan adalah responden terbanyak dari penelitian ini yaitu 16 responden atau $53.3 \%$

5. Lama Menderita DM

Penderita DM rata rata telah menderita sejak 5 dan 6 tahun,

6. Kebiasaan merokok, olahraga, dan alkohol

Pada penderita DM ada 7 responden $(23,3 \%)$ yang merokok, tidak ada yang minum alcohol, dan yang berolahraga secara teratur ada 18 responden (60\%).

7. Kualitas tidur sebelum dan sesudah Kualias tidur responden sebelum diberikan intervensi yaitu kurang sebanyak 16 responden (53.3\%), sedangkan setelah diberikan intervensi yang mengalami kualias tidur baik adalah 18 responden $(60 \%)$.

8. $\mathrm{HbA} 1 \mathrm{C}$ sebelum dan sesudah HbA1C pada penderita DM sebelum dilakukan intervensi pada kelompok intervensi yang paling rendah yaitu 5.1 dan paling tinggi 11.1 , sedangkan pada kelompok control yang paling rendah adalah 5,3 dan yang palin tinggi 11,1 . Kemudian setelah dilakukan intervensi pada kelompok intervensi HbA1c yang paling rendah adalah 5.0 dan yang paling tinggi 9.7 dengan median 6,4 , sedangkan pada kelompok kontrol yang paling rendah yaitu 5,3 dan paling rendah 11.2 dengan median 6.9.

\section{Analisis Bivariat}

1. Uji Normalitas Data

Setelah dilakukan uji normalitas data ditemukan bahwa nilai $p<0.05$ sehingga data dianggap tidak normal maka dilakukan uji alternatif Wilcoxon untuk melihat perbedaan kontrol glukosa pada pre dan post baik pada kelompok kontrol maupun intervensi sedangkan Untuk melihat perbedaan glukosa darah pada kelompok kontrol dan intervensi maka uji alternatif mann whitney karena sebaran data tidak normal.

2. Tes statistik

Pada hasil statistik, ditemukan bahwa tidak ada perbedaan pada kelompok control maupun kelompok intervensi baik sebelum maupun sesudah intervensi, dengan nilai $p=$ 0.436 sebelum dan $p=0.267$ sesudah intervensi. Sedangkan jika melihat nilai Hba1c sebelum dan sesudah pada kelompok control tetap tidak ada perbedaan namun pada kelompok intervensi terdapat perbedaan dengan nilai $p=0.005 \mathrm{Hal}$ tersebut menunjukkan bahwa terdapat pengaruh yang signifikan pemberian terapi akupresure terhadap keseimbangan glukosa darah pada pasien DM tipe 2 di PKM Jumpandang baru Makassar.

\section{PEMBAHASAN}

Hasil penelitian yang diperoleh menunjukkan ada pengaruh yang signifikan pemberian terapi akupresure terhadap keseimbangan glukosa darah pada pasien DM tipe 2 dengan nilai $p=0.005$ pada kelompok intervensi dan $p=0.977$ pada kelompok kontrol.

Pada uji statistik untuk menilai adanya perbedaan $\mathrm{HbA} 1 \mathrm{C}$ pada kelompok control dan intervensi tidak ditemukan adanya perbedaan baik itu sebelum maupun setelah intervensi, namun setelah dilakukan uji ulang dengan melihat perubahan sebelum 
dan sesudah pada kelompok intrvensi ternyata terdapat perubahan yang signifikan.

Temuan ini sejalan dengan penelitian yang dilakukan oleh (Fitrullah \& Rousdy, 2016), yang menemukan bahwa Terapi akupresur terbukti mampu mengurangi glukosa darah dan sangat membantu untuk mengurangi komplikasi akibat diabetes, Terapi akupresur dianggap sebagai terapi alternative yang paling efektif untuk mengontrol diabetes dibandingkan dengan terapi lainnya. Akupresur terbukti mampu mengurangi glukosa darah dan sangat membantu untuk mengurangi komplikasi akibat diabetes. Terapi gabungan (terapi akupresur, hipnoterapi, dan Transcendental Meditation) mungkin penting pada populasi pasien diabetes tipe 2 untuk terapi psikofisiologis tingkat lanjut ((Mehrotra \& Bajaj, 2004), (Chen et al., 2009), (Bay \& Bay, 2011)).

DM tipe 2 adalah sebuah keadaan hiperglikemia puasa yang terjadi meski tersedia insulin endogen. Kadar insulin yang dihasilkan pada DM tipe 2 berbeda beda meskipun ada. Fungsi insulin dirusak oleh resistensi insulin oleh jaringan perifer. Diman hati memproduksi glukosa lebh dari normal, karbohidrat dalam makanan tidak dimetabolisme dengan baik dan akhirnya pangkreas mengeluarkan jumlah insulin yang kurang dari kebutuhan (LeMone, Burken, \& Bauldoff, 2015).

DM merupakan penyakit degenerative yang sangat sulit untuk disembuhkan, hal yang paling bisa dilakukan adalah dengan mengurangi risiko komplikasi dengan cara mengatur glukosa darah tetap seimbang. Oelh karena itu terapi akupresur bisa menjadi salah satu alternative untuk membantu pasien tetap mengjaha glukosa darah pasien tetap stabil.

\section{KESIMPULAN}

Terdapat pengaruh yang signifikan pemberian terapi akupresure terhadap keseimbangan glukosa darah pada pasien DM tipe 2 di PKM Jumpandang baru Makassar.

\section{SARAN}

1. Untuk Puskesmas

Menjadikan akupresure sebagai pengobatan alternatif atau sebagai oendamping obat untuk membantu pasien mengjaga glukosa darah tetap seimbang sehingga kemungkinan komplikasi lebih kecil..

2. Untuk Pasien DM

Melakukan pemeriksaan glukosa darah secara rutin, melakukan pola hidup sehat, beraktivitas yang cukup, dan menerapkan akupresure sebagai langkah pencegahan.

3. Untuk Peneliti Selanjutnya.

Melakukan peneltian lanjutan dengan mengontrol variable yang dapat mengganggu, misalnya memastikan kelompok control tidak melakukan intervesni sendiri.

\section{UCAPAN TERIMAKASIH}

\section{Kepada yang terhormat :}

1. Menteri Riset, teknologi dan pendidikan tinggi, Bapak Mohammad Nasir yang telah membiayai penelitian ini melalui Hibah Eksternal Skim Penelitian Dosen Pemula (PDP).

2. Ketua STIKES Nani Hasanuddin Makassar bapak Yasir Haskas yang memberikan dukungan motivasi dan materil.

3. Kepala P3M STIKES Nani Hasanuddin Makassar, Ibu Suarnianti yang selalu memberikan motivasi kepada dosen untuk produktif menghasilkan penelitian dan pengabdian pada msyarakat

4. Kepala Puskemas JumpandangBaru Makassar

5. Responden yang bersedia bekerjasama meberikan data dan informasi sehingga penelitian ini dapat terlaksana.

\section{DAFTAR PUSTAKA}

Bay, R., \& Bay, F. (2011). Combined Therapy Using Acupressure Therapy , Hypnotherapy, and Transcendental Meditation versus Placebo in Type 2 Diabetes. Journal of Acupuncture and Meridian Studies, 4(3), 183-186. https://doi.org/10.1016/j.jams.2011.09. 006

Chen, L., Pan, J., Li, J., Jin, K., Wang, Y., \& Wang, F. (2009). Acupressure Therapy Inhibits the Development of Diabetic Complications in Chinese Patients with Type 2 Diabetes, 15(9), 1027-1032.

Fitrullah, \& Rousdy, A. (2016). Effectiveness of Acupressure at the Zusanli ( ST-36 ) Acupoint as a Comfortable Treatment 
for Diabetes Mellitus: A Pilot Study in Indonesia. Journal of Acupuncture and Meridian

Studies. https://doi.org/10.1016/j.jams.2016.12. 003

KemenKes. (2014). InfoDATIN Pusat Data dan Informasi Kementrian Kesehata RI. Jakarta. Retrieved from www.depkes.go.id\%3Einfodatindiabetes

LeMone, P., Burken, K., \& Bauldoff, G. (2015). Buku Ajar Keperawatan Medikal Bedah (Edisi 5). Jakarta: EGC.

Mehrotra, R., \& Bajaj, S. (2004). Use of complementary and alternative medicine by patients with diabetes mellitus, Volume 17(September 2004).

Pusat Data dan Informasi Kesehatan. (2014). infodatin-diabetes.pdf. Jakarta Selatan.

Ramachandran, A., Snehalatha, C., Chan, J. C. N., Chia, K. S., Shaw, J. E., \&
Zimmet, P. Z. (2016). Diabetes in Asia and the Pacific: Implications for the Global Epidemic. Diabetes Care, 39(March), 472-485. https://doi.org/10.2337/dc15-1536

Rudijanto, A., Yuwono, A., Shahab, A., Manaf, A., Pramono, B., Lindarto, D., ... Langi, Y. A. (2015). Konsensus Pengelolaan dan pencegahan diabetes melitus tipe 2 di indonesia 2015 (Pertama). Pengurus Besar Perkumpulan Endokrinologi Indonesia (PB PERKENI).

Soekidjo Notoatmojo. (2005). Metodologi Penelitian Kesehatan (Revisi). Jakarta: Rineka Cipta.

Tsai, Y., Kann, N., Tung, T., Chao, Y., Lin, C., Chang, K., \& Chang, S. (2012). Impact of subjective sleep quality on glycemic control in type 2 diabetes mellitus, (July 2011), 30-35. https://doi.org/10.1093/fampra/cmr041 